\title{
Nitrato de potássio e retirada do pericarpo na germinação e na avaliação do vigor de sementes de crambe
}

\section{Potassium nitrate and pericarp removal in germination and in evaluation crambe seed vigor}

\author{
Anísio da Silva Nunes ${ }^{1 *}$; Luiz Carlos Ferreira de Souza ${ }^{2}$; \\ Silvana de Paula Quintão Scalon ${ }^{3}$; Jennifer Pagnoncelli ${ }^{4}$
}

Resumo

Objetivou-se neste trabalho avaliar a influência do nitrato de potássio $\left(\mathrm{KNO}_{3}\right)$ e da retirada do pericarpo no teste de germinação, bem como a viabilidade de uso do teste de condutividade elétrica para a avaliação do vigor de sementes de crambe. O delineamento utilizado nos dois experimentos foi o inteiramente casualizado, com os tratamentos dispostos em esquema fatorial $2 \times 2 \times 4$ no teste de germinação (com e sem $\mathrm{KNO}_{3}$, com e sem pericarpo e quatro lotes de sementes); e esquema fatorial $2 \times 4$ nos testes de emergência e condutividade elétrica (com e sem pericarpo e quatro lotes de sementes). A concentração de nitrato de potássio $\left(\mathrm{KNO}_{3}\right)$ na solução de umedecimento do substrato foi de $0,2 \%$ e a retirada do pericarpo foi realizada manualmente. Foram realizadas avaliações de grau de umidade, germinação, primeira contagem de germinação, índice de velocidade de germinação, comprimento de raiz e parte aérea de plântulas, massa seca total e emergência de plântulas e condutividade elétrica. O nitrato de potássio não aumenta a porcentagem ou a velocidade de germinação de sementes de crambe. A retirada manual do pericarpo aumenta a velocidade, mas não afeta a porcentagem de germinação das sementes. $O$ teste de condutividade elétrica pode ser recomendado para identificar diferenças de vigor entre lotes de sementes de crambe.

Palavras-chave: Qualidade fisiológica, testes de vigor, condutividade elétrica, Crambe abyssinica

\begin{abstract}
The objective of this study was to evaluate the potassium nitrate influence $\left(\mathrm{KNO}_{3}\right)$ and the pericarp removal in germination, as well as the viability of the electrical conductivity test for evaluation crambe seed vigor. The experimental design used in the two trials was completely randomized design with treatments arranged in a $2 \times 2 \times 4$ factorial in the germination test (with and without $\mathrm{KNO}_{3}$, with and without pericarp and four lots of seeds) and $2 \times 4$ factorial in the tests and emergency electrical conductivity (with and without pericarp and four seed lots). The potassium nitrate concentration $\left(\mathrm{KNO}_{3}\right)$ in the wetting of the substrate solution was $0.2 \%$ and the pericarp removal has been performed manually. Evaluations were made of moisture content, final germination, first counting, germination speed index, root and shoot length, total dry mass and seedling emergence and electrical conductivity. Potassium nitrate does not increase the percentage or the germination rate of crambe seed. The manual removal of the pericarp increases the speed, but does not affect the germination of seeds. The electrical conductivity can be recommended to identify vigor differences among seed lots of crambe.
\end{abstract}

Key words: Physiological quality, vigor tests, electrical conductivity, Crambe abyssinica

\footnotetext{
${ }^{1}$ Prof. Adjunto, Universidade do Estado de Mato Grosso, UNEMAT, Campus de Tangará da Serra, MT. E-mail: anisio@unemat.br

2 Prof. Associado, Universidade Federal da Grande Dourados, UFGD, Dourados, MS. E-mail: luizsouza@ufgd.edu.br

Prof Adjunta, UFGD, Dourados, MS. E-mail: silvanascalon@ufgd.edu.br

${ }^{4}$ Eng $^{\mathrm{a}}$ Agr ${ }^{\mathrm{a}}$, Agrotec, Pedro Juan Caballero, Paraguai. E-mail: jenipagnoncelli@hotmail.com

* Autor para correspondência
} 


\section{Introdução}

O crescente interesse da sociedade por fontes alternativas de energia, que contribuam para a redução da emissão de gases causadores do efeito estufa, tem estimulado a criação de modelos energéticos baseados no aproveitamento de fontes renováveis (CONSTANTINO et al., 2014). Nesse sentido, o Brasil é um dos países com maior potencial para a produção de combustíveis a partir de biomassa, por contar com extensas áreas cultiváveis, possibilidade de múltiplos cultivos no ano e mais de 200 espécies de plantas oleaginosas que podem ser utilizadas como fonte de matériaprima para a produção de biodiesel (AMARO et al., 2014; MELLO; PAULILLO; VIAN, 2007).

Assim, várias oleaginosas estão sendo testadas para a produção de biodiesel, como soja, mamona, dendê, girassol, amendoim, colza, babaçu, entre outras (MASETTO et al., 2013; RUAS et al., 2010). Entretanto, a grande dificuldade para o avanço deste modelo energético tem sido a oferta de matéria-prima suficiente para atender a demanda do mercado por combustíveis renováveis. Por isso, faz-se necessário o estudo de culturas agrícolas mecanizáveis, que possam ser cultivadas em grandes áreas e que não sejam comercializadas como alimento humano ou animal (CRUZ et al., 2013).

Entre as culturas que podem preencher esta lacuna na oferta de matéria-prima para a produção de biodiesel em grande escala está o crambe (Crambe abyssinica Hochst), uma planta da família Brassicaceae que possui tolerância à seca e à geada, boa produtividade e precocidade. Devido a estas características, o crambe é recomendado para o cultivo da safrinha na região Centro-Oeste do Brasil, com a semeadura realizada logo após a colheita da soja (PITOL, 2008).

As sementes de crambe possuem forma esférica e são envolvidas por uma estrutura denominada pericarpo que, de modo geral, possui a função básica de proteger as sementes contra danos mecânicos, funcionando também como barreira para a entrada de microorganismos e permitindo que as sementes possam ser armazenadas por longos períodos, sem perda significativa da germinação (RUAS et al., 2010). Em algumas espécies, o pericarpo pode ocasionar elevada desuniformidade de germinação, ou até mesmo a ausência de germinação (MARCOS FILHO, 2005). Nesse caso, a retirada dessa estrutura pode acelerar o processo de germinação.

Entre as recomendações das Regras para Análise de Sementes (BRASIL, 2009) para os testes de germinação em sementes de crambe está a adição de solução aquosa de nitrato de potássio $\left(\mathrm{KNO}_{3}\right)$ ao substrato de germinação, com o intuito de superar a dormência fisiológica das sementes (FARIA et al., 2012).

A qualidade fisiológica das sementes é de grande importância para obtenção de germinação e emergência uniformes, necessárias para o estabelecimento do estande adequado para as culturas agrícolas (MENDONÇA; RAMOS; FESSEL, 2003). Neste contexto, sementes de alto vigor são elementos básicos e fundamentais para o sucesso do cultivo e, por isso, o aprimoramento dos testes de germinação e vigor se faz necessário para detectar variações sutis na qualidade de lotes de sementes de espécies cultivadas.

Além da necessidade de padronização de metodologias e interpretação dos resultados, os testes de vigor devem apresentar relação com a emergência de plântulas em campo, rapidez, objetividade, simplicidade, baixo custo e reprodutibilidade. Entre os testes rápidos, o de condutividade elétrica tem sido utilizado com frequência para a avaliação do vigor das sementes (CRUZ et al., 2013). O teste de condutividade elétrica avalia a qualidade das sementes indiretamente, por meio da determinação da quantidade de lixiviados na solução de embebição das sementes (VIEIRA et al., 2002). Assim, pesquisas realizadas com diferentes espécies têm mostrado que o decréscimo na germinação e no vigor é diretamente proporcional ao aumento da 
liberação de solutos, o que possibilita a indicação da condutividade elétrica para a determinação do vigor de lotes de sementes de algumas espécies (MARCOS FILHO, 2005).

As pesquisas com sementes de crambe ainda são incipientes na literatura e até o momento poucos trabalhos validam os métodos para a análise da qualidade fisiológica das sementes dessa espécie. Diante disso, objetivou-se neste trabalho avaliar a influência do nitrato de potássio $\left(\mathrm{KNO}_{3}\right)$ e da retirada do pericarpo no teste de germinação, bem como a viabilidade do teste de condutividade elétrica para a avaliação do vigor de sementes de crambe.

\section{Material e Métodos}

A pesquisa foi divida em três ensaios e realizada no Laboratório de Análise de Sementes da Faculdade Anhanguera de Dourados, com quatro lotes de sementes de crambe, cultivar FMS Brilhante, produzidos em Mato Grosso do Sul e armazenados por nove meses. Os lotes de sementes foram obtidos de diferentes locais de produção, em uma mesma safra agrícola.

O delineamento utilizado nos dois experimentos foi o inteiramente casualizado, com os tratamentos dispostos em esquema fatorial $2 \times 2 \times 4$ no teste de germinação (com e sem $\mathrm{KNO}_{3}$, com e sem pericarpo e quatro lotes de sementes); e esquema fatorial $2 \times 4$ nos testes de emergência e condutividade elétrica (com e sem pericarpo e quatro lotes de sementes). A concentração de nitrato de potássio $\left(\mathrm{KNO}_{3}\right)$ na solução de umedecimento do substrato foi de 0,2\% (BRASIL, 2009) e a retirada do pericarpo foi realizada manualmente. Todos os tratamentos foram avaliados em quatro repetições de 50 sementes, totalizando 200 sementes por tratamento. As avaliações realizadas durante os testes de germinação, emergência e condutividade elétrica são descritas a seguir.

Grau de umidade - realizado pelo método da estufa a $105 \pm 3^{\circ} \mathrm{C}$, durante 24 horas, (BRASIL,
2009), utilizando-se duas amostras de $5 \mathrm{~g}$ de sementes para cada lote. Os resultados foram expressos em porcentagem (base úmida) por lote.

Germinação - quatro repetições de 50 sementes por tratamento foram distribuídas sobre duas folhas de papel germitest, umedecidas com água destilada e deionizada ou com solução aquosa de $\mathrm{KNO}_{3}$ a $0,2 \%$, de acordo com o tratamento, equivalente a 2,5 vezes a massa do substrato seco, e acondicionadas em caixas gerbox transparente $(11 \times 11 \times 3,5 \mathrm{~cm})$. Após a semeadura, as caixas foram fechadas e mantidas em câmara de germinação a $25{ }^{\circ} \mathrm{C}$, sem fotoperíodo. As avaliações foram efetuadas aos quatro (primeira contagem) e aos sete dias após a semeadura, computando-se a porcentagem de plântulas normais (BRASIL, 2009).

Índice de velocidade de germinação (IVG) - determinado mediante contagens diárias do número de sementes germinadas, no mesmo horário, durante o teste de germinação. $\mathrm{O}$ índice foi calculado de acordo com a equação proposta por Maguire (1962).

Comprimento de plântulas - após a contagem final do teste de germinação, foram realizadas medições da raiz e da parte aérea de dez plântulas normais tomadas ao acaso de cada repetição, com auxílio de uma régua graduada em centímetros, sendo os resultados expressos em cm por plântula.

Relação parte aérea/raiz - obtida por meio da divisão do comprimento da parte área pelo comprimento da raiz.

Massa seca de plântulas - as mesmas plântulas da avaliação de comprimento de plântulas foram acondicionadas em sacos de papel e levadas à estufa de circulação forçada de ar a $65^{\circ} \mathrm{C}$, até atingir massa constante (48 horas) e, decorrido esse período, as massas foram determinadas em balança analítica com precisão de $0,001 \mathrm{~g}$, sendo os resultados expressos em g por plântula.

Emergência de plântulas - realizada com quatro repetições de 50 sementes por tratamento, 
semeadas em bandejas plásticas contendo solo e areia na proporção de 1:1 (NAKAGAWA, 1994), acondicionadas em casa de vegetação durante vinte dias computando-se a porcentagem de plântulas normais emergidas.

Índice de velocidade de emergência realizado conjuntamente com o teste de emergência de plântulas, foram avaliadas diariamente o número de plântulas emergidas, até a estabilização da emergência, para o cálculo do índice de velocidade de emergência (MAGUIRE, 1962). Após a contagem final da emergência, que ocorreu no vigésimo dia após a semeadura, dez plântulas normais de cada bandeja foram medidas, da raiz até a parte aérea, com auxílio de uma régua graduada em centímetros, sendo os resultados expressos em cm plântula ${ }^{-1}$.

Condutividade elétrica - foram utilizadas quatro repetições de 50 sementes para cada tratamento. As sementes tiveram sua massa determinada em balança de precisão de 0,0001g e em seguida foram colocadas em copos plásticos descartáveis contendo $75 \mathrm{~mL}$ de água destilada e deionizada, durante um período de quatro horas, a $25^{\circ} \mathrm{C}$, de acordo com estudo realizado previamente. As leituras da condutividade elétrica foram realizadas em condutivímetro Digimed DM-31, e os valores médios obtidos para cada lote, expressos em $\mu \mathrm{S} \mathrm{cm}^{-1} \mathrm{~g}^{-1}$ de semente.

$\mathrm{Na}$ análise estatística, os dados percentuais foram normalizados pela transformação em arco seno da raiz quadrada de x $100^{-1}$, porém, nas tabelas e figuras, estão apresentados os dados originais. Aplicou-se o teste F para análise da variância e, quando esta foi significativa, utilizou-se o teste Tukey com 5\% de significância nas comparações entre as médias das variáveis estudadas.

\section{Resultados e Discussão}

Os teores iniciais de água nas sementes de crambe dos quatro lotes variam entre 9,3 e 10,8\%, sendo, portanto, adequados para o armazenamento e a comercialização das mesmas. As sementes oleaginosas, por possuírem alto conteúdo de óleo, devem ser armazenadas com grau de umidade inferior ao recomendado para as sementes amiláceas, que é de 11\% (MARCOS FILHO, 2005). Não foi constatada interação significativa entre os fatores analisados nos experimentos.

O umedecimento do substrato com solução aquosa de $\mathrm{KNO}_{3}$ a $0,2 \%$ não alterou a primeira contagem de germinação, a germinação, o comprimento e a massa seca de plântulas (Tabela 1). Esses resultados contradizem as recomendações das Regras para Análise de Sementes (BRASIL, 2009), que indicam a utilização de $\mathrm{KNO}_{3}$ para testes de germinação de sementes de crambe, sem levar em consideração o tempo de armazenamento. $\mathrm{O} \mathrm{KNO}_{3}$ é frequentemente recomendado para a superação de dormência em sementes de gramíneas forrageiras, hortaliças e ornamentais, entretanto, a dormência das sementes de crambe diminui naturalmente com o tempo de armazenamento (COSTA et al., 2012). Desta forma, observou-se que não há necessidade de utilização de $\mathrm{KNO}_{3}$ em testes de germinação com sementes de crambe armazenadas por períodos de nove meses ou mais. 
Tabela 1. Porcentagem de germinação na primeira contagem (PC), porcentagem de germinação (G), Índice de Velocidade de Germinação (IVG), relação parte aérea/raiz (PA/R), comprimento de plântulas (CP), em cm plântula ${ }^{-1}$, e massa seca de plântulas (MS), em g plântula ${ }^{-1}$, em função de tratamentos físico e químico na avaliação qualidade fisiológica de lotes de sementes de crambe.

\begin{tabular}{lcccccc}
\hline \multicolumn{1}{c}{ Tratamentos } & PC & G & IVG & PA/R & CP & MS \\
\hline $\mathrm{Com} \mathrm{KNO}_{3}$ & 14,0 & 70,6 & 13,8 & $4,43 \mathrm{a}$ & 7,27 & 0,040 \\
$\mathrm{Sem} \mathrm{KNO}_{3}$ & 16,1 & 69,8 & 14,5 & $1,71 \mathrm{~b}$ & 6,88 & 0,039 \\
DMS & 2,2 & 3,7 & 0,8 & 0,64 & 1,03 & 0,09 \\
Sem pericarpo & $18,9 \mathrm{a}$ & 75,3 & $14,7 \mathrm{a}$ & 3,18 & 8,32 & 0,044 \\
Com pericarpo & $16,6 \mathrm{~b}$ & 72,1 & $13,6 \mathrm{~b}$ & 2,95 & 7,54 & 0,037 \\
DMS & 2,2 & 3,7 & 0,8 & 0,64 & 1,03 & 0,009 \\
Lote 1 & $23,6 \mathrm{a}$ & $84,4 \mathrm{a}$ & $17,5 \mathrm{a}$ & 3,67 & $8,68 \mathrm{a}$ & 0,038 \\
Lote 2 & $14,5 \mathrm{~b}$ & $63,0 \mathrm{~b}$ & $12,5 \mathrm{~b}$ & 3,01 & $6,12 \mathrm{~b}$ & 0,047 \\
Lote 3 & $21,0 \mathrm{a}$ & $80,3 \mathrm{a}$ & $16,3 \mathrm{a}$ & 3,09 & $8,12 \mathrm{a}$ & 0,035 \\
Lote 4 & $10,6 \mathrm{~b}$ & $53,3 \mathrm{c}$ & $10,3 \mathrm{c}$ & 2,49 & $5,91 \mathrm{~b}$ & 0,039 \\
DMS & 4,2 & 6,8 & 1,5 & 1,20 & 1,92 & 0,016 \\
CV $(\%)$ & 21,4 & 10,4 & 11,1 & 20,7 & 18,8 & 23,6 \\
\hline
\end{tabular}

Médias seguidas por letras diferentes, em uma mesma coluna, diferem significativamente entre si pelo Teste de Tukey a 5\% de probabilidade. DMS = Diferença Mínima Significativa. CV = Coeficiente de Variação.

Fonte: Elaboração dos autores.

Embora não tenha afetado a velocidade e a porcentagem de germinação e a massa seca das plântulas de crambe, a utilização de $\mathrm{KNO}_{3}$ na solução de embebição das sementes promoveu o alongamento da parte aérea das plântulas, evidenciado pela maior relação parte aérea/raiz sem o correspondente aumento na massa seca de plântulas (Tabela 1). $\mathrm{O} \mathrm{KNO}_{3}$ é utilizado como estimulador de crescimento, agindo sobre os promotores de crescimento de algumas espécies, como Hypericum brasiliense (FARON et al., 2004) e Guarea guinonia (CASTRO et al., 1999).

A retirada manual do pericarpo das unidades de dispersão de crambe proporcionou maiores velocidades de germinação e emergência, mas não influenciou as porcentagens destas avaliações (Tabelas 1 e 2). A remoção do pericarpo dos frutos pode aumentar a velocidade de emergência das plântulas; porém, aumenta também a possibilidade de danos mecânicos às sementes, que poderiam reduzir a germinação e tornar as sementes mais vulneráveis ao ataque de fungos e insetos. Assim, pode-se inferir que embora o pericarpo não represente uma barreira impermeável para as sementes de crambe armazenadas, sua retirada acelera a embebição das sementes e, em consequência, todo o processo germinativo.

Os resultados das avaliações de primeira contagem de germinação e índice de velocidade de germinação apresentados na Tabela 1, bem como os das avaliações de primeira contagem de emergência e índice de velocidade de emergência expostos na Tabela 2, permitem identificar diferenças estatisticamente significativas entre os lotes, classificando-os em diferentes níveis de qualidade fisiológica. Em testes de velocidade de germinação, lotes cujas sementes germinam mais rápido são considerados mais vigorosos, havendo, portanto, relação direta entre velocidade de germinação e vigor das sementes. Assim, lotes com desempenho germinativo semelhante podem diferir quanto à velocidade de germinação (MARCOS FILHO, 2005) e, assim, quanto ao nível de vigor. O teste de primeira contagem também avalia, indiretamente, a velocidade de germinação; de tal forma que, quanto maior a porcentagem de plântulas normais computadas na data da primeira contagem, maior será o vigor do lote (NAKAGAWA, 1999). 
Tabela 2. Porcentagem de emergência na primeira contagem (PC), porcentagem de emergência (\%E), Índice de Velocidade de Emergência (IVE) e comprimento de plântulas $(\mathrm{CP})$, em $\mathrm{cm}$ plântula ${ }^{-1}$, em função de tratamentos de sementes na avaliação da emergência de plântulas em lotes de sementes de crambe.

\begin{tabular}{lcccc}
\hline Tratamentos & PC & $\mathbf{\% E}$ & IVE & $\mathbf{C P}$ \\
\hline Sem pericarpo & $17,2 \mathrm{a}$ & 62,9 & $6,0 \mathrm{a}$ & 2,9 \\
Com pericarpo & $13,1 \mathrm{~b}$ & 57,3 & $3,9 \mathrm{~b}$ & 2,8 \\
DMS & 3,7 & 7,6 & 0,8 & 0,3 \\
Lote 1 & $31,8 \mathrm{a}$ & $78,5 \mathrm{a}$ & $8,0 \mathrm{a}$ & $3,2 \mathrm{a}$ \\
Lote 2 & $7,5 \mathrm{~b}$ & $36,8 \mathrm{~b}$ & $2,9 \mathrm{~b}$ & $2,4 \mathrm{~b}$ \\
Lote 3 & $28,6 \mathrm{a}$ & $73,8 \mathrm{a}$ & $7,3 \mathrm{a}$ & $3,0 \mathrm{a}$ \\
Lote 4 & $3,6 \mathrm{~b}$ & $22,0 \mathrm{c}$ & $1,3 \mathrm{c}$ & $2,2 \mathrm{~b}$ \\
DMS & 6,9 & 14,4 & 1,5 & 0,5 \\
CV $(\%)$ & 18,1 & 21,3 & 21,8 & 12,9 \\
\hline
\end{tabular}

Médias seguidas por letras diferentes, em uma mesma coluna, diferem significativamente entre si pelo Teste de Tukey a 5\% de probabilidade. DMS = Diferença Mínima Significativa. $\mathrm{CV}=$ Coeficiente de Variação.

Fonte: Elaboração dos autores.

A utilização de $\mathrm{KNO}_{3}$ na solução de embebição das sementes e a retirada do pericarpo não influenciaram a massa seca de plântulas (Tabela 1). E, ao contrário do comprimento de plântulas, não foi possível identificar por meio da massa seca as diferenças de vigor existentes entre os lotes de sementes de crambe. As condições oferecidas no teste foram favoráveis e as partes das plântulas normais avaliadas tiveram crescimento rápido, uniforme e comprimentos pouco discrepantes, mesmo para aqueles lotes com menor número de sementes germinadas. Estes resultados divergem daqueles encontrados na cultura da soja (HENNING et al., 2010), sorgo (SANTOS et al., 2008) e mamona (OLIVEIRA et al., 2010), em que a massa seca de plântulas pode ser indicada para expressar o vigor de lotes de sementes, mas corroboram com resultados encontrados na cultura do arroz (MENEZES; SILVEIRA, 1995).

Com base nos testes de germinação e vigor realizados (Tabelas 1 e 2) foi possível identificar os lotes 1 e 3, agrupados em um mesmo patamar de vigor, como os de melhor qualidade fisiológica, seguidos do lote $2 \mathrm{e}$, por último, do lote 4 . Resultados semelhantes foram observados no teste de condutividade elétrica (Figura 1A), que se baseia na avaliação indireta da qualidade fisiológica por meio da determinação da quantidade de lixiviados na solução de embebição das sementes. Os menores valores, correspondentes à menor liberação de exsudatos, indicam maior vigor, devido à menor intensidade de desorganização dos sistemas das membranas celulares (VIEIRA et al, 2002). Os maiores valores de condutividade elétrica, em $\mu \mathrm{S}$ $\mathrm{cm}^{-1} \mathrm{~g}^{-1}$, para os tratamentos com a retirada manual do pericarpo (Figura 1B) confirmam os resultados observados nas avaliações de primeira contagem de germinação e do IVG, em que a ausência do pericarpo promoveu o aumento na velocidade de embebição. Além disso, a retirada do pericarpo facilita a saída de solutos dos frutos para a solução de embebição.

Figura 1. Condutividade elétrica $\left(\mu \mathrm{S} \mathrm{cm}^{-1} \mathrm{~g}^{-1}\right)$ de quatro lotes (1A) de sementes de crambe, com e sem pericarpo (1B), imersas em $75 \mathrm{~mL}$ de água, a $25^{\circ} \mathrm{C}$, após quatro horas de embebição.
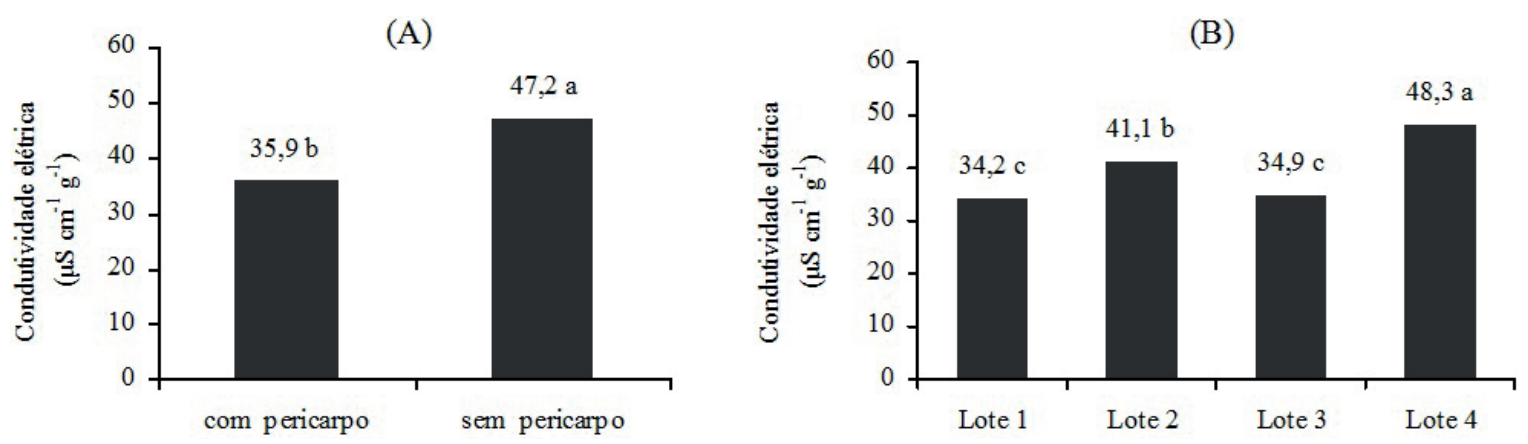

Fonte: Elaboração dos autores. 
O teste de condutividade elétrica, se comparado a outros testes de vigor, possui como vantagens a praticidade, a rapidez na obtenção dos resultados e a possibilidade de aplicação em sementes pequenas, como as sementes de crambe. Enquanto os testes de germinação ou emergência para a cultura do crambe possuem a duração de sete dias (BRASIL, 2009), o teste de condutividade elétrica evidenciou a diferença entre os lotes em um período de quatro horas. Este ganho em tempo, praticidade e economia de material é de grande importância para laboratórios de análise de sementes, sobretudo aqueles que realizam grande número de análises por dia. A condutividade elétrica também foi recomendada como teste de vigor para outras culturas com sementes pequenas, como azevém (LOPES; FRANKE, 2010), rúcula (TORRES; PEREIRA, 2010), gergelim (TORRES et al., 2009), milheto (GASPAR; NAKAGAWA, 2002) e tomate (SÁ, 1999).

\section{Conclusões}

A utilização do nitrato de potássio não aumenta a germinação ou a velocidade de germinação de sementes de crambe armazenadas por períodos superiores a nove meses; a retirada manual do pericarpo aumenta a velocidade mas não altera a germinação das sementes.

$\mathrm{O}$ teste de condutividade elétrica pode ser recomendado para identificar diferenças de vigor entre lotes de sementes de crambe.

\section{Agradecimentos}

À Fundação de Apoio ao Desenvolvimento do Ensino, Ciência e Tecnologia do Estado de Mato Grosso do Sul (Fundect), pela concessão de bolsa de estudos ao primeiro autor.

\section{Referências}

AMARO, H. T. R.; DAVID, A. M. S. S.; SILVA NETA, I. C.; ASSIS, M. O.; ARAÚJO, E. F.; ARAÚJO, R. F. Teste de envelhecimento acelerado em sementes de crambe (Crambe abyssinica Hochst), cultivar FMS Brilhante. Revista Ceres, Viçosa, MG, v. 61, n. 2, p. 202-208, 2014.

BRASIL. Ministério da Agricultura, Pecuária e Abastecimento. Regras para análise de sementes. Ministério da Agricultura, Pecuária e Abastecimento. Secretaria de Defesa Agropecuária. Brasília: MAPA/ ACS, 2009. 395 p.

CASTRO, E. M.; ALVARENGA, A. A.; ALMEIDA, L. P.; GAVILANES, M. L.; PEREIRA, P. A.; Influência do ácido giberélico e do nitrato de potássio na germinação de Guarea guidonia (L) Sleum. Revista Árvore, Viçosa, MG, v. 23, n. 2, p. 255-258, 1999.

CONSTANTINO, A. F.; LACERDA JÚNIOR, V.; SANTOS, R. B.; GRECO, S. J.; SILVA, R. C.; BARBOSA, L. L.; CASTRO, E. V. R.; FREITAS, J. C. C. Análise do teor e da qualidade dos lipídeos presentes em sementes de oleaginosas por rmn de baixo campo. Química Nova, São Paulo, v. 37, n. 1, p. 10-17, 2014.

COSTA, L. M.; RESENDE, O.; GONÇALVES, D. N.; SOUZA, K. A. Qualidade dos frutos de crambe durante o armazenamento. Revista Brasileira de Sementes, Londrina, v. 34, n. 2, p. 239-301, 2012.

CRUZ, S. M.; NERY, M. C.; ROCHA, A. S.; PINHO, E. V. R.; ANDRADE, P. C. R.; DIAS, D. C. F. S. Vigor tests for evaluation of crambe (Crambe abyssinica Hochst) seed quality. Journal of Seed Science, Londrina, v. 35, n. 4, p. 485-494, 2013.

FARIA，R. Q.; TEIXEIRA， I. R.; DEVILLA, I.A.; ASCHERI, D. P. R.; RESENDE, O. Cinética de secagem de sementes de crambe. Revista Brasileira de Engenharia Agrícola e Ambiental, Campina Grande, v. 16, n. 5, p. 573-583, 2012.

FARON, M. L. B.; PERECIN, M. B.; LAGO, A. A.; BOVI, O. A.; MAIA, N. B. Temperatura, nitrato de potássio e fotoperíodo na germinação de sementes de Hypericum perforatum L. e H. brasiliense Choisy. Bragantia, Campinas, v. 63, n. 2, p. 193-199, 2004.

GASPAR, C. M.; NAKAGAWA, J. Teste de condutividade elétrica em função do período e da temperatura de embebição para sementes de milheto. Revista Brasileira de Sementes, Londrina, v. 24, n. 2, p. 82-89, 2002. 
HENNING, F. A.; MERTZ, L. M.; JACOB JUNIOR, E. A.; MACHADO, R. D.; FISS, G.; ZIMMER, P. D. Composição química e mobilização de reservas em sementes de soja de alto e baixo vigor. Bragantia, Campinas, v. 69, n. 3, p. 727-734, 2010.

LOPES, R. R.; FRANKE, L. B. Teste de condutividade elétrica para avaliação da qualidade fisiológica de sementes de azevém (Lolium multiflorum L.). Revista Brasileira de Sementes, Londrina, v. 32, n. 1 p. 123-130, 2010.

MAGUIRE, J. D. Speed of germination-aid in selection and evaluation for seedling emergence and vigor. Crop Science, Madison, v. 2, n. 1, p. 176-177, 1962.

MARCOS FILHO, J. Fisiologia de sementes de plantas cultivadas. Piracicaba: FEALQ, 2005. 495 p.

MASETTO, T. E.; GORDIN, C. R. B.; QUADROS, J. B.; REZENDE, R. K. S.; SCALON, S. P. Q. Armazenamento de sementes de Crambe abyssinica Hochst. ex R. E. Fr. em diferentes embalagens e ambientes. Revista Ceres, Viçosa, MG, v. 60, n. 5, p. 646-652, 2013.

MELlO, F. O. T.; PAULILLO, L. F.; VIAN, C. E. F. O Biodiesel no Brasil: Panorama, perspectivas e desafios. Informações Econômicas, São Paulo, v. 37, n. 1, p. 28 40, 2007.

MENDONÇA, E. A. F.; RAMOS, N. P.; FESSEL, S. A. Adequação da metodologia do teste de deterioração controlada para sementes de brócolis (Brassica oleracea L. - var. Itálica). Revista Brasileira de Sementes, Londrina, v. 25, n. 1, p. 18-24, 2003.

MENEZES, N. L.; SILVEIRA, T. L. D. Métodos para avaliar a qualidade fisiológica de sementes de arroz. Scientia Agricola, Piracicaba, v. 52, n. 2, p. 350-359, 1995.

NAKAGAWA, J. Testes de vigor baseados na avaliação das plântulas. In: VIEIRA, R. D.; CARVALHO, N. M. (Ed.). Testes de vigor em sementes. Jaboticabal: FUNEP, 1994. p. 49-86.
NAKAGAWA, J. Testes de vigor baseados no desempenho das plântulas. In: KRZYZANOSKI, F. C.; VIEIRA, R. D.; FRANÇA NETO, J. B. Vigor de sementes: conceitos e testes. Londrina: ABRATES, 1999. p. 1-24.

OLIVEIRA, R. H.; SOUZA, M. J. L.; MORAIS, O. M.; GUIMARÃES, B. V. C.; PEREIRA JÚNIOR, H. A. Potencial fisiológico de sementes de mamona tratadas com micronutrientes. Acta Scientiarum. Agronomy, Maringá, v. 32, n. 4, p. 701-707, 2010.

PITOL, C. Cultura do Crambe. In: PITOL, C.; BROCH, D. L.; ROSCOE, R. (Ed.). Tecnologia e produção: milho safrinha e culturas de inverno. Maracaju: Fundação MS, 2008. p. 85-88.

RUAS, R. A. A.; NASCIMENTO, G. B.; BERGAMO, E. P.; DAUR JÚNIOR, R. H.; ARRUDA, R. G. Embebição e germinação de sementes de crambe (Crambe abyssinica). Pesquisa Agropecuária Tropical, Goiânia, v. 40, n. 1, p. 61-65, 2010.

SÁ, M. E. Condutividade elétrica em sementes de tomate (Lycopersicon lycopersicum L.). Scientia Agricola, Piracicaba, v. 56, n. 1, p. 13-20, 1999.

SANTOS, H. C.; VIANA, J. S.; GONÇALVES, E. P.; BRUNO, R. L. A.; FRAGA, V. S. Qualidade fisiológica de sementes de sorgo em resposta a adubação com zinco. Revista Caatinga, Mossoró, v. 21, n. 1, p. 64-74, 2008.

TORRES, S. B.; MEDEIROS, M. A.; TOSTA, M. S.; COSTA, G. M. M. Teste de condutividade elétrica em sementes de gergelim. Revista Brasileira de Sementes, Londrina, v. 31, n. 3, p. 70-77, 2009.

TORRES, S. B.; PEREIRA, R. A. Condutividade elétrica em sementes de rúcula. Revista Brasileira de Sementes, Londrina, v. 32, n. 4 p. 58-70, 2010.

VIEIRA, R. D.; PENARIOL, A. L.; PERECIN, D.; PANOBIANCO, M. Condutividade elétrica e teor de água inicial das sementes de soja. Pesquisa Agropecuária Brasileira, Brasília, v. 37, n. 9, p. 1333-1338, 2002. 